\title{
Enhancing pharmacists' role in developing countries to overcome the challenge of antimicrobial resistance: a narrative review
}

\author{
M. H. F. Sakeena ${ }^{1,2^{*}} \mathbb{D}$, Alexandra A. Bennett ${ }^{3}$ and Andrew J. McLachlan ${ }^{2}$
}

\begin{abstract}
Background: Antimicrobial resistance (AMR) is a global health challenge and developing countries are more vulnerable to the adverse health impacts of AMR. Health care workers including pharmacists can play a key role to support the appropriate use of antimicrobials in developing countries and reduce AMR.

Objective: The aim of this review is to investigate the role of pharmacists in the appropriate use of antibiotics and to identify how the pharmacists' role can be enhanced to combat AMR in developing countries.

Method: The databases MEDLINE, EMBASE, Web of Science and Google Scholar were searched for articles published between 2000 and the end of August 2017 that involved studies on the role of pharmacists in developing countries, the expanded services of pharmacists in patient care in developed countries and pharmacists' contributions in antimicrobial use in both developed and developing nations.

Key findings: In developing countries pharmacists role in patient care are relatively limited. However, in developed nations, the pharmacists' role has expanded to provide multifaceted services in patient care resulting in improved health outcomes from clinical services and reduced health care costs. Success stories of pharmacist-led programs in combating AMR demonstrates that appropriately trained pharmacists can be part of the solution to overcome the global challenge of AMR. Pharmacists can provide education to patients enabling them to use antibiotics appropriately. They can also provide guidance to their healthcare colleagues on appropriate antibiotic prescribing.

Conclusions: This review highlights that appropriately trained pharmacists integrated into the health care system can make a significant impact in minimising inappropriate antibiotic use in developing countries. Strengthening and enhancing the pharmacists' role in developing countries has the potential to positively impact the global issue of AMR.
\end{abstract}

Keywords: Antibiotics, Antimicrobial resistance, Pharmacists, Pharmacy education, Pharmacy services, Developing country

\section{Background}

Antimicrobial resistance (AMR) is a serious global health challenge [1]. It is predicted that by 2050 there will be more than ten million deaths per year attributed to AMR [2]. Further, it is predicted that the greatest number of these deaths will be in developing countries [2]. Therefore, there is an urgent need to take action to minimize the emergence of antimicrobial resistant bacteria in developing countries $[3,4]$. The management of

\footnotetext{
* Correspondence: h.sakeena@gmail.com

${ }^{1}$ Department of Pharmacy, Faculty of Allied Health Sciences, University of Peradeniya, Peradeniya, Sri Lanka

${ }^{2}$ Sydney Pharmacy School, The University of Sydney, Sydney, NSW, Australia Full list of author information is available at the end of the article
}

development and spread of AMR requires a multifaceted approach, including the participation of all healthcare workers [5]. According to the first objective of the World Health Organization (WHO) global action plan on AMR, avoiding overuse and misuse of antibiotics requires healthcare professionals awareness and understanding of AMR with effective communication, education and training [6]. In this context, healthcare professionals have a key role to play to optimize the use of antibiotics in the community.

Pharmacists are important members of the healthcare team and they play a major role in medicine use and the provision of advice regarding appropriate medicines use [7]. Education and training of pharmacists has the

(c) The Author(s). 2018 Open Access This article is distributed under the terms of the Creative Commons Attribution 4.0 International License (http://creativecommons.org/licenses/by/4.0/), which permits unrestricted use, distribution, and 
potential to influence the behaviour of healthcare team members and consumers [8] as part of a multidimensional strategy for changing practice and ensure the quality use of antibiotics [9]. They are well placed to improve the understanding of antibiotics and inform their judicious use by direct contact with consumers in the community [10] and in hospital [11]. Consumer education is an important component of the fight against AMR and pharmacists can improve consumer's awareness of safe and appropriate medication practices concerning antibiotics [12]. Comprehensive and relevant education and training on the use of antibiotics and AMR is essential for pharmacists in order that they may take a leading role in changing behaviours regarding antibiotic consumption in all healthcare settings.

Numerous studies have highlighted that inappropriate medication practices are relatively common in the community and hospital settings of developing countries [13-15]. For example, use of antibiotics without medical prescriptions is a well described practice, despite regulation prohibiting the supply of antibiotics in this manner [16-18]. Absence of qualified pharmacists is one factor that has contributed to these inappropriate practices in community pharmacies [19]. Similarly, overprescribing of antibiotics in hospitals in developing countries is common, and the lack of clinical pharmacists in hospitals in developing countries may be a contributing factor [20].

Several reviews have addressed and proposed possible solutions to the challenge of AMR in developing countries $[21,22]$. However, there are currently relatively few reports on how pharmacists can play a role in overcoming the challenge of AMR in developing countries. In order to ensure the recommended multidisciplinary approaches taken (WHO), strategies that reduce AMR in developing countries, should consider the contribution of appropriately qualified and trained pharmacists. Therefore, the aim of this narrative review is to investigate how the pharmacists' role can be further enhanced to provide judicious and appropriate antibiotic use in developing countries.

\section{Method}

\section{Literature search strategy}

A literature search was conducted to identify articles, published between 2000 and the end of August 2017 that involved studies on antimicrobial use or AMR involving pharmacists in community and hospital settings of developing countries using databases such as EMBASE, MEDLINE and Web of Science.

The following 'Medical Subject Headings' (MeSH) terms were used to search articles: (Antibiotics.mp.) OR (Anti-Bacterial Agents) OR (Antimicrobial agents.mp. or Anti-Infective Agents) OR (Drug Resistance, Bacterial or Antimicrobial resistance.mp. or Drug Resistance, Microbial) AND (Community pharmacy.mp. or Pharmacies) OR
(Community Pharmacy Services/ or Pharmacists/ or community pharmacist.mp.) OR (Professional Role/ or Pharmacy Service, Hospital/ or Pharmacy/ or Pharmacists/ or Pharmacy practice.mp. or Pharmaceutical Services) OR (Clinical pharmacy.mp.) AND (Pharmacist OR Community pharmacy OR Community pharmacist OR Clinical Pharmacy OR Clinical pharmacist OR Pharmaceutical care) AND (Attitude OR Perception OR Barriers).

The following keywords were used to search articles in Web of Science: ("Antibiotics" OR "Antimicrobials") AND ("Community pharmacy" OR "Community pharmacist") AND ("Hospital pharmacist" OR "Clinical pharmacist"). Google Scholar was also used to search for articles with the appropriate keywords. Cross-references of articles identified using these databases were also searched. National pharmacy journals of developing countries were also searched for relevant articles.

\section{Selection of articles}

This review focuses on three main areas; firstly, the current role of pharmacists in developing countries; secondly, pharmacists' services in patient care in developed countries; and, thirdly, success stories involving pharmacists that optimised antibiotic use and reduced AMR in both developed and developing nations. Articles were scrutinised to identify those that addressed the above. Only articles and abstracts published in English were included in the review. This will not limit this review, because authors have searched different national journals from developing countries which publishes articles in English and available online.

\section{Results}

Pharmacists' roles - Current scenario in developing countries The challenges and barriers related to pharmacists' roles in pharmaceutical care in developing countries identified from recently published research articles are presented in Table 1. These studies are based on pharmacists' reports from a variety of developing countries including those in Asia [23-26], Africa [27, 28], South America [29] and the Middle-East [30-32]. These results highlight that challenges exist in both community [23-26, $29,30]$ and hospital [27, 28, 31] provision of pharmaceutical care services. The major barriers to the delivery of comprehensive pharmacy services include the shortage of pharmacists, the lack of pharmaceutical care training programs and institutional obstacles.

\section{Pharmacists' involvement in optimising medicines}

Practicing pharmacists providing pharmaceutical care services are central to coordinating and optimising medicines among healthcare professionals, patients and the general public is presented in Fig. 1. This centric role of pharmacists is important for the quality use of antibiotics. 


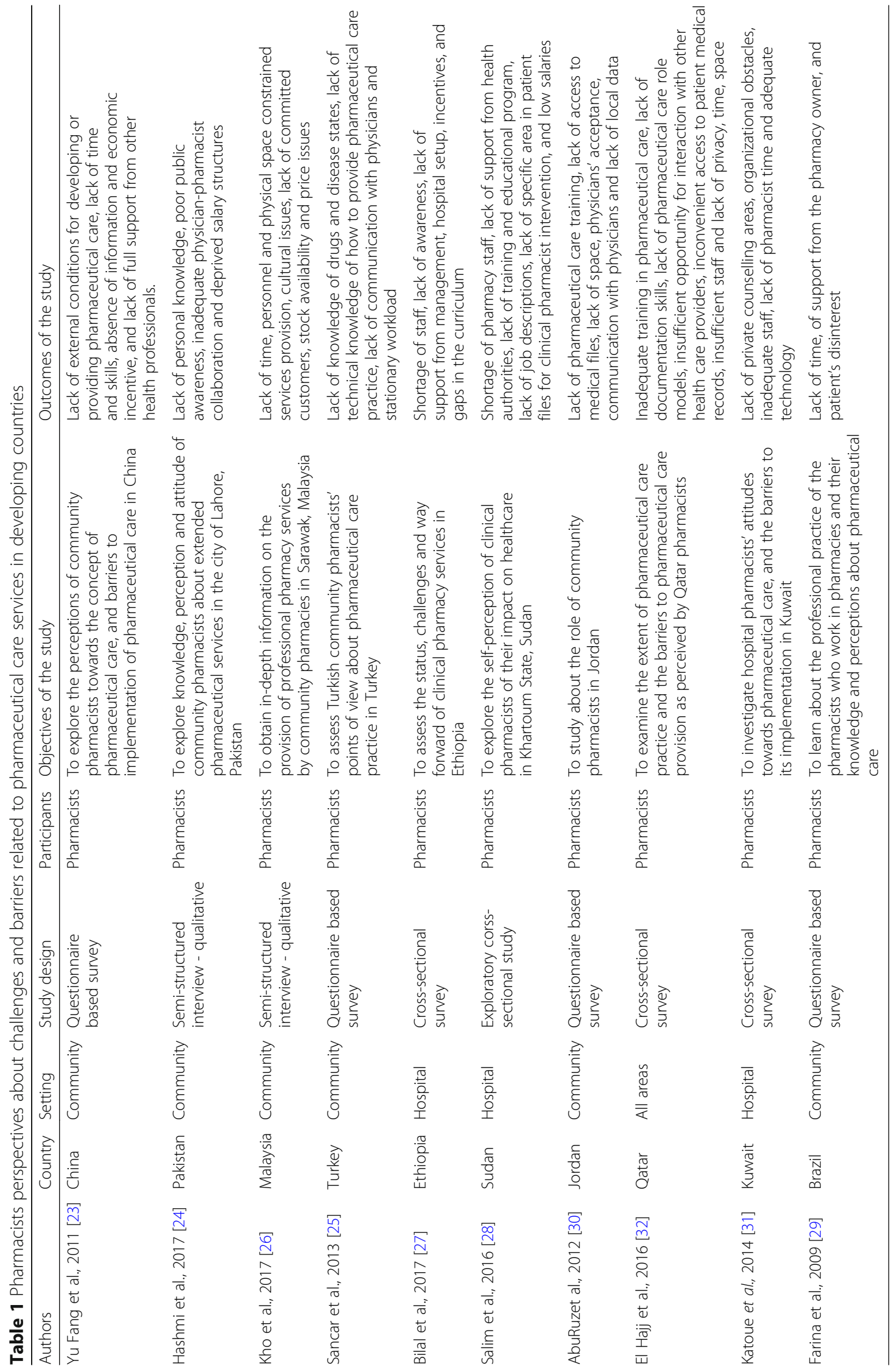




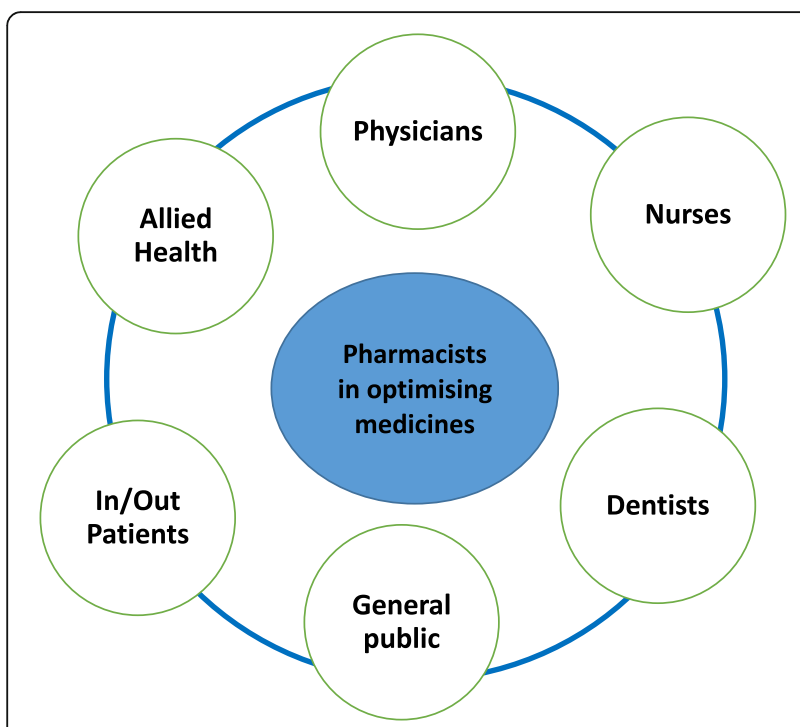

Fig. 1 Adequate education and extensive training are important for practicing pharmacists and their pharmaceutical services are central to coordinating and optimising antibiotics among healthcare professionals, patients and the general public

\section{AMR-related interventions led by pharmacists in developing and developed countries}

Role of pharmacists' in enhancing antibiotic use and combating AMR from recently published studies in developing and developed countries are presented in Table 2. The inclusion of pharmacists in different care settings has shown significant improvement in the quality use of antibiotics. Studies showing positive impacts are from both developing [9, 33-35] and developed [10, 36-42] nations. These studies also demonstrate that pharmacists can improve appropriate antibiotic use in hospital [9, 33-37, 39-41] and community $[10,38,42]$ settings.

\section{Discussion}

\section{Statement of principal findings}

Significant progress in delivering pharmaceutical care services by the pharmacists has occurred within the pharmacy profession in the past few decades. There is a notable shift from medicine supply roles to pharmacistdelivered patient-centred services for the purpose of improving rational use of medications and ultimately enhancing the quality of life of patients. In many developed nations, pharmaceutical care services as a practice based profession was introduced many years ago. These developed nations are now experiencing the positive outcomes of the expanded roles of pharmacists, which directly impact patient care and quality use of medicines. However, in many developing countries, pharmaceutical care services are still limited to traditional pharmacy practices such as procurement of drugs, extemporaneous compounding, dispensing of prescriptions and selling of medicines.
Therefore, an understanding the expanded roles of pharmacists in the current rapidly changing healthcare system of developed countries and the benefits they can bring is important for the development of healthcare systems in developing countries. One of the major outcomes of enhanced pharmacists' roles is the more appropriate use of antibiotics among health care professionals, patients in different settings of care and the general public. The importance of pharmacist-led antibiotic stewardship programs has long been recognised in the developed nations. The establishment of well qualified and trained pharmacy workforce in developing countries has the potential to reduce antibiotics overuse and misuse.

\section{Context of these findings Pharmacists' role in developing countries}

The pharmacy profession still has an emerging professional status in developing countries [43]. Pharmacy services in developing countries tend to be limited to roles in drug manufacturing, medicines procurement, drug dispensing and drug supply chain and storage [44]. Pharmacists are well recognized and well remunerated for their role within the pharmaceutical industry in developing countries [43] and there is a strong demand for employment in this field. However, in developing countries, pharmaceutical care services, clinical roles or pharmacy practice more generally are not yet well recognised as key roles for pharmacists [23]. In contrast, in developed nations pharmaceutical care services are considered as integral components of the health care systems [45]. Pharmacists in developing countries are not actively involved in providing patient care related services [46] such as infection control, immunization, diabetes, lipid management, coronary heart disease, skin cancer prevention, mental health, sexual health, prevention of substance abuse, smoking cessation, nutrition and physical activity $[45,47]$ and there is limited professional involvement in initiatives related to rational medicine use [47]. Pharmacists are underutilized, their education and training under-recognised and their potential roles in patient care can be viewed as missed opportunities for optimising the health of populations in developing countries $[48,49]$.

There are numerous challenges and barriers faced by pharmacists in developing countries to implement and maintain sustainable pharmaceutical care services [23, 27, 30]. Most developing countries are struggling with a shortage of pharmacists [27, 28, 31, 32, 43], inadequate education and training for pharmacists $[24,25,27,28,30$, 32 , and support from other health care professionals [23$25,28,30,32]$. Even though pharmacists from developing countries show great enthusiasm to promote and to devote themselves to the provision of pharmaceutical care services in their countries [27], efforts made to 


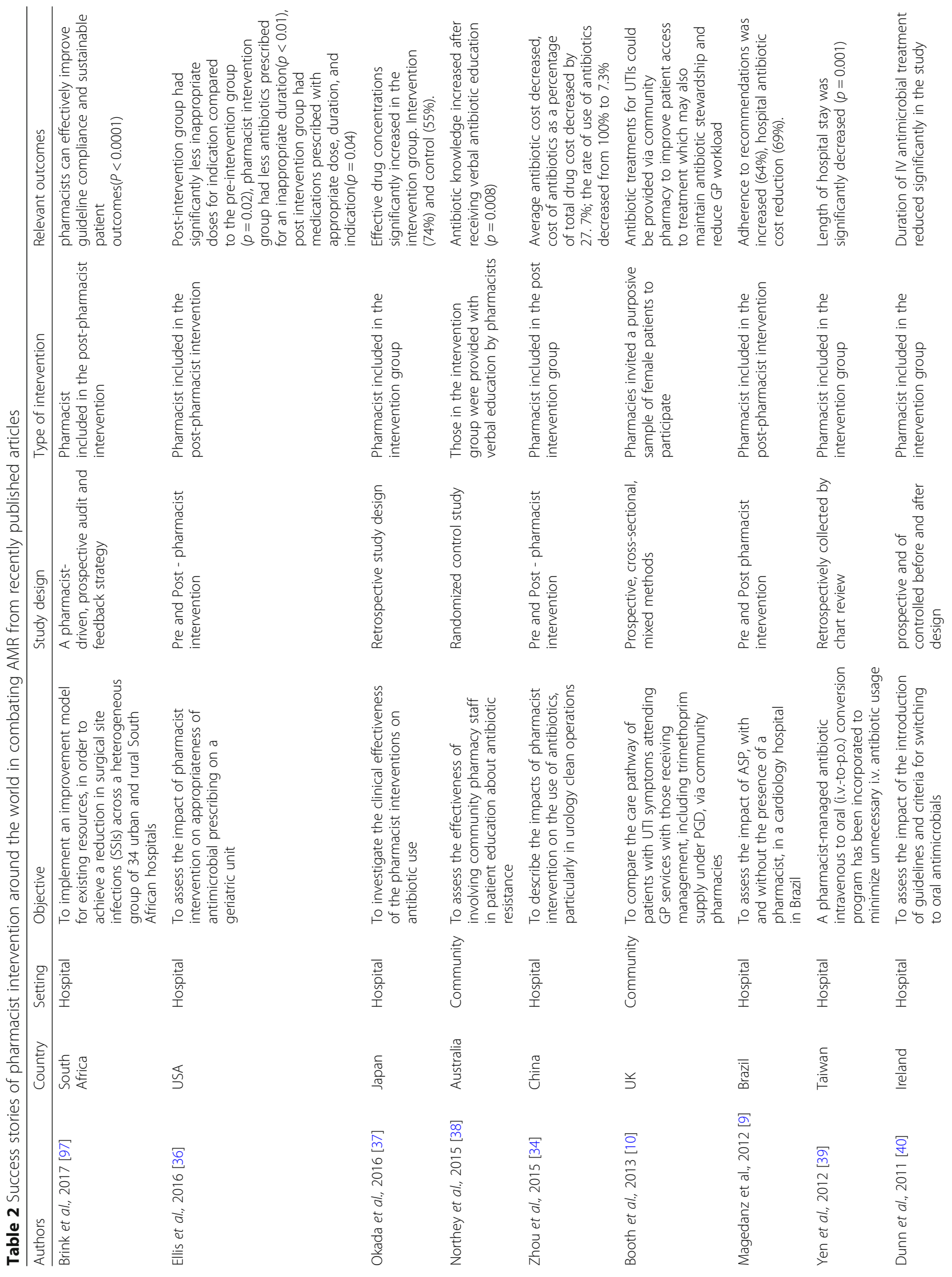




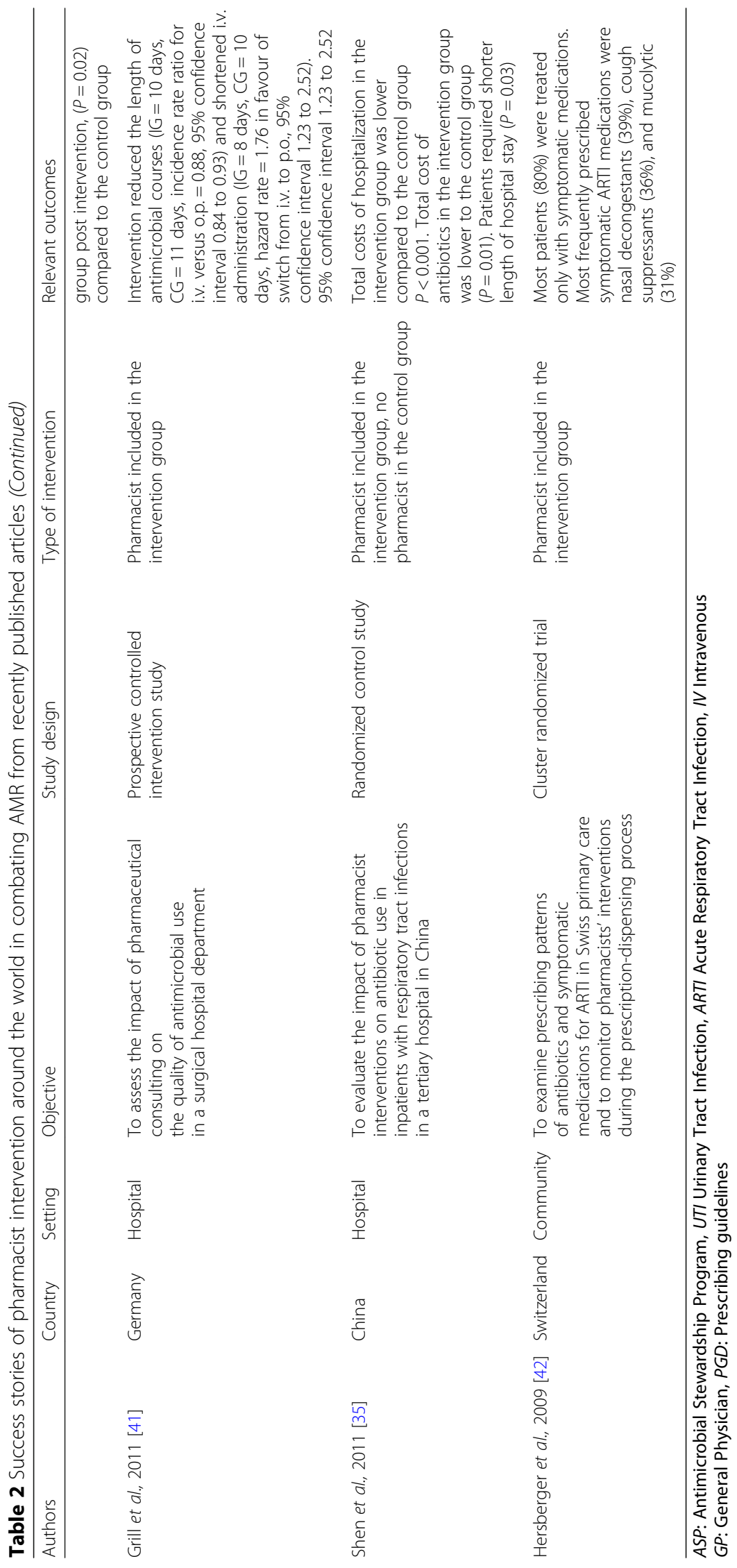


institutionalize pharmaceutical care services is minimal in many developing countries [27, 45, 47]. The underdeveloped nature of pharmaceutical care services in developing countries is considered a primary reason for inappropriate and inadequate medication practices [45, 47].

If pharmacists are to provide patient care services in developing countries, it is essential to remove these major barriers [50]. These could be overcome by increasing employment opportunities for pharmacists, improving educational programmes and facilitating effective collaboration with other health professionals [46]. It is essential that adequate education and extensive training of pharmacists is provided by the tertiary education sector of developing countries, and that integrate pharmacists' roles are integrated with those of physicians and other health care providers in the health care systems of developing countries to optimise patient care, and ultimately reduce health care costs and improve public health.

\section{Pharmacists' contributions in developed nations}

Extended pharmacists' roles are well established in the developed nations [51]. Pharmacist-delivered pharmaceutical care services have long been established and are widely developed in the United States (US) [52], United Kingdom (UK) [10], Canada [53], Australia [54, 55] and New Zealand [56]. They have produced notably positive outcomes in both hospital [52] and community settings [10] in these countries. Adequate education and extensive training of pharmacists in these countries has produced pharmacists, able to deliver high quality pharmaceutical care services [57]. As a result, these countries have integrated pharmacists as an important members of their health care teams [58]. Acceptance of pharmacists' extended roles by physicians and other health care workers has produced significant positive outcomes in patient care in these countries $[59,60]$. The numerous interventions in medication management reported in these countries demonstrate the high level of trust of pharmacists by the general public in these countries [61].

An example of an expanded pharmacist roles includes clinical pharmacist activities in Australian hospital emergency departments (ED) [62]. ED medical and nursing staff highly value pharmacist-delivered clinically significant medication interventions at an early stage of patient entry into the hospital. Similarly, the important role of the community pharmacy in the health sector is well established in many developed nations [10] with, for example, pharmacists interventions leading to reduced prescription errors in the community setting [63].

In developed nations, pharmacists' role has expanded to provide a variety of services including pharmacovigilance activities [64], pharmacist prescribing [65], disease state management [66], medication reconciliation- inpatient [67] and outpatient [68], discharge management and counselling [69], home and residential aged care medication reviews [70], pharmacists in general practices [71], and pharmacists-led clinics (diabetes and cardiovascular) [72]. The provision of and outcomes from these expanded services are appreciated by physicians [73, 74] and the public $[75,76]$. Such enhanced pharmacist roles in developed nations have demonstrated improved clinical and therapeutic outcomes [77] and reduced health care costs [53]. The expanded roles require appropriate education and training programs for pharmacists and integration of pharmacists into the health care system. Consequently it is recommended that developing countries through policy and program development and adoption ensure appropriate education and training programs for pharmacists and implement healthcare practice frameworks that recognise the potential of such training and education and integrate pharmacists into their healthcare systems and multidisciplinary delivery of patient care.

\section{Pharmacists' contributions in combating AMR in both developed and developing nations}

Pharmacists' contribution in optimal antimicrobial use is an essential component in the fight against growing AMR. Many developed countries have achieved success with the implementation of antimicrobial stewardship (AMS) programs that include pharmacists. [78, 79] AMS programs aim to ensure judicious, appropriate and safe antibiotic use. Guntenet al., 2007 [80], clearly describes the clinical and economic outcomes that can result from antibiotic-related pharmaceutical services. In this review, pharmacist's successful contributions to reducing the development and spread of AMR have been identified. The crucial role of pharmacists in promoting safe and cost-effective use of antimicrobial agents is acknowledged and implemented in the healthcare systems of numerous countries $[9,10,33-42]$. A noteworthy example of this role is their role in the care of critically ill patients with infectious diseases in Intensive Care Units (ICU) which results in improved clinical and economic outcomes [81].

In contrast, developing countries have not yet implemented pharmacist-led initiatives such as pharmacist-led AMS programs [82]. In these countries, pharmacists could play a key role in minimizing unnecessary prescribing of antibiotics and developing local prescribing guidelines according to diagnoses and local antibiotic susceptibility patterns [83]. Education regarding infection-control practices is also an important avenue for pharmacist involvement. Given their ready accessibility by the public, community pharmacists should be proactive in regard to educating the public about important infection-control practices such as general hygiene, hand hygiene, cough etiquette, immunizations and staying home when sick. Although these strategies may seem like common sense, 
patient understanding of these basic infection-control practices should not be overestimated. Adequately trained pharmacists can educate patients about management of viral, bacterial and common fungal infections.

Hence, there is a necessity to ensure suitably qualified pharmacists in developing countries through delivery of high quality and expanded pharmacy education. Education on infectious diseases, their management and AMR should be given increased attention in the pharmacy curriculum. The resultant knowledge, behaviours and skills should be evaluated prior to qualification and continuing professional development in this therapeutic area maintained if developing countries are to avoid the negative impact of inappropriate antibiotic utilization and AMR that is forecast in the developing countries in the near future [84].

\section{Strengths and weaknesses of the study}

To our knowledge, there have been few reviews of the actual or potential role of pharmacists in developing countries that combat the challenge of AMR. This review explored the current situation of pharmacists in developing countries, the role of pharmacists in pharmaceutical care in the developed world and the success stories of pharmacist-related interventions in advancing prudent antibiotic use. This review highlights significant justification for enhancing pharmacists' roles in developing countries and the steps that should be taken by these countries to achieve these expanded pharmacists' roles. This review was limited to studies published in English, and therefore relevant studies published non-English languages would have been missed.

\section{Meaning of this review: Possible mechanisms and implications for clinicians or policymakers}

Given the emerging nature of pharmaceutical care services, some developing countries have incorporated pharmaceutical care courses, such as clinical pharmacy, albeit in their infancy, within the national pharmacy curriculum [85]. However, many developing countries remain reluctant to offer a clinically significant role for pharmacists within their healthcare systems. For example, there are very few defined positions for clinical pharmacists in hospitals and within the health care sector in many developing countries [86]. Adequate hospital access for clinical training of pharmacy students remains a barrier [87]. Finding well qualified and experienced professionals to lead teaching in clinical pharmacy, is a further challenge. Some countries have managed to recruit experienced international clinical pharmacy educators to develop and support clinical pharmacy education programs that include pharmacist-led models of care [88, 89]. If developing countries are to avoid the consequences of indiscriminate and inappropriate antibiotic use it is essential that the knowledge and skills of all members of the healthcare team be harnessed including those of pharmacists and that the opportunity to deliver this knowledge and skills is incorporated within the healthcare system. Pharmacists with appropriate educational background and clinical training can play a crucial role in reducing the burden of antimicrobial resistance in hospital settings [90]. Interventions minimizing inappropriate use of antibiotics by clinical pharmacists are well reported in literature [91-93]. Pharmacists can assist to eliminate the misconceptions about antibiotic use and educate the patients, prescribers and other health care professional on appropriate antibiotic utilization.

Furthermore, pharmacists can provide their services and support to physicians, nurses and other healthcare professionals to optimize antibiotic use, provide updated information about antibiotics and the adverse drug effects of antibiotics and monitor antibiotic use within healthcare settings. Establishing collaborative team based relationships between physicians and pharmacists will allow for improved patient outcomes [94]. Antibiotic guidelines are not available in many developing countries, and pharmacists can play a key role in their development [95]. Counselling of patients by pharmacists about appropriate antibiotic use is an important role for pharmacists [96] and would be facilitated by the implementation of pharmaceutical service provision in developing countries. [70].

\section{Unanswered questions and future research}

While the evidence for expanded pharmacist roles in developed countries is robust and generally translatable, it is nevertheless important that local evaluation of interventions by appropriately educated and trained pharmacists occurs. Factors related to success and failure of local programs will need to be identified to inform further program development and implementation. Importantly, programs expanding clinical pharmacist services are likely to be assisted with local and national policy and appropriate remuneration. Initiatives such as guideline development will also assist these programs. Although this review has focussed on pharmacist education and training, the training of other healthcare professionals also requires evaluation and possible overhaul. Education that highlights the benefits of health care provision when providers are team players will be advantageous.

\section{Conclusion}

As has occurred in developed countries, the provision of qualified trained pharmacists and pharmacist integration into healthcare systems has the potential to make a significant impact on inappropriate antibiotic use in developing countries. Although this is only one of a number of interventions necessary to overcome the problem of 
catastrophic AMR in developing countries, it is achievable. Studies from developed countries have demonstrated that cost-effective optimal patient outcomes are achieved when pharmacists roles are enhanced within the health care system, when they are recognised as part of the health care team to provide advice on the rational and safe use of medicines, and university curricula and continuing professional education provide theoretical and practical knowledge and skills regarding the quality use of medicines. Antimicrobial stewardship involving pharmacists should be established in hospitals to ensure judicious and appropriate antimicrobial use. Adoption of these strategies will assist developing countries overcome their increased vulnerability to growing AMR.

\section{Acknowledgements}

M.H.F. Sakeena is supported by an Australian Government Endeavour Postgraduate Scholarship (ID: 4565_2015) for her PhD studies at The University of Sydney, NSW, Australia.

\section{Availability of data and materials}

This narrative review was based on data extracted from published papers available in the public domain.

\section{Authors' contributions}

MHFS, AAB and AJM were equally involved in the development of the proposal, study design and in writing the manuscript. All authors revised and approved the submission of the manuscript.

\section{Competing interests}

The authors declare that they have no competing interests.

\section{Publisher's Note}

Springer Nature remains neutral with regard to jurisdictional claims in published maps and institutional affiliations.

\section{Author details}

${ }^{1}$ Department of Pharmacy, Faculty of Allied Health Sciences, University of Peradeniya, Peradeniya, Sri Lanka. ${ }^{2}$ Sydney Pharmacy School, The University of Sydney, Sydney, NSW, Australia. ${ }^{3}$ NSW Therapeutic Advisory Group, Sydney, NSW, Australia.

\section{Received: 2 March 2018 Accepted: 19 April 2018}

Published online: 02 May 2018

\section{References}

1. Marston HD, Dixon DM, Knisely JM, Palmore TN, Fauci AS. Antimicrobial resistance. JAMA. 2016;316(11):1193-204.

2. Antimicrobial Resistance: Tackling a crisis for the health and wealth of nations [https://amr-review.org/sites/default/files/AMR\%20Review\%20 Paper\%20-\%20Tackling\%20a\%20crisis\%20for\%20the\%20health\%20and\%20 wealth\%20of\%20nations_1.pdf. Accessed 27 Feb 2018.

3. Laxminarayan $\mathrm{R}$, Chaudhury RR. Antibiotic resistance in India: drivers and opportunities for action. PLoS Med. 2016:13(3):e1001974.

4. Okeke IN, Laxminarayan $R$, Bhutta ZA, Duse AG, Jenkins P, O'Brien TF Antimicrobial resistance in developing countries. Part I: recent trends and current status. Lancet Infect Dis. 2005:5.

5. Lee $\mathrm{C}-\mathrm{R}$, Cho $\mathbb{H}$, Jeong BC, Lee $\mathrm{SH}$. Strategies to Minimize Antibiotic Resistance. Int J Environ Res Public Health. 2013:10(9):4274-305.

6. WHO. Global action plan on antimicrobial resistance. 2015 [cited 2017 Jan 5]; Available from: http://apps.who.int/iris/bitstream/10665/193736/1/ 9789241509763_eng.pdf?ua=1. Accessed 5 Jan 2017.

7. Williford SL, Johnson DF. Impact of pharmacist counseling on medication knowledge and compliance. Mil Med. 1995;160(11):561-4.

8. Smith RE, Olin BR. Wellness: pharmacy Education's role and responsibility. Am J Pharm Educ. 2010;74(4):69.
9. Magedanz L, Silliprandi EM, dos Santos RP. Impact of the pharmacist on a multidisciplinary team in an antimicrobial stewardship program: a quasiexperimental study. Int J Clin Pharm. 2012;34(2):290-4.

10. Booth JL, Mullen AB, Thomson DAM, Johnstone C, Galbraith SJ, Bryson SM, MCGovern EM. Antibiotic treatment of urinary tract infection by community pharmacists: a cross-sectional study. Br J Gen Pract. 2013; 63(609): $244-9$

11. Farley TM, Shelsky C, Powell S, Farris KB, Carter BL. Effect of clinical pharmacist intervention on medication discrepancies following hospital discharge. Int J Clin Pharm. 2014:36(2):430-7.

12. Awad A, Abahussain E. Health promotion and education activities of community pharmacists in Kuwait. Pharm World Sci. 2010;32(2):146-53.

13. Ogbo PU, Aina BA, Aderemi-Williams RI. Management of acute diarrhea in children by community pharmacists in Lagos, Nigeria. Pharm Pract. 2014; 12(1):376

14. Al-Niemat SI, Aljbouri TM, Goussous LS, Efaishat RA, Salah RK. Antibiotic prescribing patterns in outpatient emergency clinics at queen Rania Al Abdullah II Children's hospital, Jordan, 2013. Oman Med J. 2014;29(4): 250-4.

15. Ab Rahman N, Teng CL, Sivasampu S. Antibiotic prescribing in public and private practice: a cross-sectional study in primary care clinics in Malaysia. BMC Infect Dis. 2016;16:208.

16. Shet A, Sundaresan S, Forsberg BC. Pharmacy-based dispensing of antimicrobial agents without prescription in India: appropriateness and cost burden in the private sector. Antimicrob Resist Infect Control. 2015:4(1):55.

17. Almaaytah A, Mukattash TL, Hajaj J. Dispensing of non-prescribed antibiotics in Jordan. Patient Prefer Adherence. 2015:9:1389-95.

18. Erku DA, Mekuria AB, Surur AS, Gebresillassie BM. Extent of dispensing prescription-only medications without a prescription in community drug retail outlets in Addis Ababa, Ethiopia: a simulated-patient study. Drug Healthc Patient Saf. 2016;8:65-70.

19. Chang J, Ye D, Lv B, Jiang M, Zhu S, Yan K, Tian Y, Fang Y. Sale of antibiotics without a prescription at community pharmacies in urban China: a multicentre cross-sectional survey. J Antimicrob Chemother. 2017;72(4):1235-42.

20. Walia K, Ohri VC, Mathai D. Antimicrobial stewardship Programme of I: antimicrobial stewardship programme (AMSP) practices in India. Indian J Med Res. 2015;142(2):130-8.

21. Padget $M$, Guillemot $D$, Delarocque-Astagneau E. Measuring antibiotic consumption in low-income countries: a systematic review and integrative approach. Int J Antimicrob Agents. 2016;48(1):27-32.

22. Miller R, Goodman C. Performance of retail pharmacies in low- and middle-income Asian settings: a systematic review. Health Policy Plan. 2016;31(7):940-53.

23. Fang $Y$, Yang $S$, Feng $B, N i$, Z Zhang K. Pharmacists' perception of pharmaceutical care in community pharmacy: a questionnaire survey in Northwest China. Health Soc Care Community. 2011;19(2):189-97.

24. Hashmi FK, Hassali MA, Khalid A, Saleem F, Aljadhey H, Babar ZUD, Bashaar M. A qualitative study exploring perceptions and attitudes of community pharmacists about extended pharmacy services in Lahore,Pakistan. BMC Health Serv Res. 2017;17(1):500

25. Sancar M, Okuyan B, Apikoglu-Rabus S, lzzettin FV. Opinion and knowledge towards pharmaceutical care of the pharmacists participated in clinical pharmacy and pharmaceutical care continuing education program. Turkish J Pharmaceutical Sci. 2013;10(2):245-54.

26. Kho BP, Hassali MA, Lim CJ, Saleem F. A qualitative study exploring professional pharmacy services offered by community pharmacies in the state of Sarawak, Malaysia. J Pharm Health Serv Res. 2017;8(3):201-8.

27. Bilal Al, Tilahun Z, Gebretekle GB, Ayalneh B, Hailemeskel B, Engidawork E. Current status, challenges and the way forward for clinical pharmacy service in Ethiopian public hospitals. BMC Health Serv Res. 2017;17(1):359.

28. Salim AM, Elhada AH, Elgizoli B. Exploring clinical pharmacists' perception of their impact on healthcare in Khartoum state, Sudan. J Res Pharm Pract. 2016;5(4):272-8

29. Farina SS, Romano-Lieber NS. Pharmaceutical care in pharmacies: is there a changing process? Saúde e Sociedade. 2009;18:7-18.

30. AbuRuz S, Al-Ghazawi M, Snyder A. Pharmaceutical care in a communitybased practice setting in Jordan: where are we now with our attitudes and perceived barriers? Int J Pharm Pract. 2012;20(2):71-9.

31. Katoue MG, Awad Al, Schwinghammer TL, Kombian SB. Pharmaceutical care in Kuwait: hospital pharmacists' perspectives. Int J Clin Pharm. 2014;36(6):1170-8 
32. El Hajj MS, Al-Saeed HS, Khaja M. Qatar pharmacists' understanding, attitudes, practice and perceived barriers related to providing pharmaceutical care. Int J Clin Pharm. 2016;38(2):330-43.

33. Brink AJ, Messina AP, Feldman C, Richards GA, Becker PJ, Goff DA, Bauer KA, Nathwani D, van den Bergh D. Antimicrobial stewardship across 47 south African hospitals: an implementation study. Lancet Infect Dis. 2016;16(9):1017-25.

34. Zhou Y, Ma LY, Zhao X, Tian SH, Sun LY, Cui YM. Impact of pharmacist intervention on antibiotic use and prophylactic antibiotic use in urology clean operations. J Clin Pharm Ther. 2015;40(4):404-8.

35. Shen J, Sun Q, Zhou X, Wei Y, Qi Y, Zhu J, Yan T. Pharmacist interventions on antibiotic use in inpatients with respiratory tract infections in a Chinese hospital. Int J Clin Pharm. 2011;33(6):929-33.

36. Ellis K, Rubal-Peace G, Chang V, Liang E, Wong N, Campbell S. Antimicrobial stewardship for a geriatric behavioral health population. Antibiotics. 2016;5(1):8.

37. Okada N, Fushitani S, Azuma M, Nakamura S, Nakamura T, Teraoka K, Watanabe H, Abe M, Kawazoe K, Ishizawa K. Clinical evaluation of pharmacist interventions in patients treated with anti-methicillin-resistant Staphylococcus aureus agents in a hematological Ward. Biol Pharm Bull. 2016;39(2):295-300.

38. Northey A, McGuren T, Stupans I. Patients' antibiotic knowledge: a trial assessing the impact of verbal education. Int J Pharm Pract. 2015;23(2):158-60.

39. Yen YH, Chen HY, Wuan-Jin L, Lin YM, Shen WC, Cheng KJ. Clinical and economic impact of a pharmacist-managed i.V.-to-p.O. conversion service for levofloxacin in Taiwan. Int J Clin Pharmacol Ther. 2012;50(2):136-41.

40. Dunn K, O'Reilly A, Silke B, Rogers T, Bergin C. Implementing a pharmacistled sequential antimicrobial therapy strategy: a controlled before-and-after study. Int J Clin Pharm. 2011;33(2):208-14.

41. Grill E, Weber A, Lohmann S, Vetter-Kerkhoff C, Strobl R, Jauch K-W. Effects of pharmaceutical counselling on antimicrobial use in surgical wards: intervention study with historical control group. Pharmacoepidemiol Drug Saf. 2011;20(7):739-46.

42. Hersberger KE, Botomino A, Sarkar R, Tschudi P, Bucher HC, Briel M. Prescribed medications and pharmacy interventions for acute respiratory tract infections in Swiss primary care. J Clin Pharm Ther. 2009;34(4):387-95.

43. Azhar S, Hassali MA, Ibrahim MIM, Ahmad M, Masood I, Shafie AA. The role of pharmacists in developing countries: the current scenario in Pakistan. Hum Resour Health. 2009;7(1):54.

44. Basak SC, Sathyanarayana D. Pharmacy education in India. Am J Pharm Educ. 2010;74(4):68.

45. Fang $Y$, Yang $S$, Zhou S, Jiang M, Liu J. Community pharmacy practice in China: past, present and future. Int J Clin Pharm. 2013;35(4):520-8.

46. Parthasarathi G, Ramesh M, Nyfort-Hansen K, Nagavi BG. Clinical pharmacy in a south Indian teaching hospital. Ann Pharmacother. 2002;36(5):927-32.

47. Basak SC, van Mil JWF, Sathyanarayana D. The changing roles of pharmacists in community pharmacies: perception of reality in India. Pharm World Sci. 2009;31 (6):612-8.

48. Alanazi A, Alfadl A, Hussain A. Pharmaceutical care in the community pharmacies of Saudi Arabia: present status and possibilities for improvement. Saudi J Med Med Sci. 2016;4(1):9-14.

49. Anderson $\mathrm{S}$. The state of the world's pharmacy: a portrait of the pharmacy profession. J Interprof Care. 2002;16(4):391-404.

50. Tumkur A, Muragundi PM, Shetty R, Naik A. Pharmaceutical care: need of the hour in India. J Young Pharm. 2012;4(4):282-6.

51. Khdour MR, Kidney JC, Smyth BM, MCElnay JC. Clinical pharmacy-led disease and medicine management programme for patients with COPD. Br J Clin Pharmacol. 2009;68(4):588-98.

52. Schimmelfing JT, Brookhart AL, Fountain KM, Goode JK. Pharmacist intervention in patient selection of nonprescription and self-care products. J Am Pharm Assoc (2003). 2017:57(1):86-9. e81

53. Marra C, Johnston K, Santschi V, Tsuyuki RT. Cost-effectiveness of pharmacist care for managing hypertension in Canada. Can Pharm J (Ott). 2017;150(3):184-97.

54. Krass I, Armour CL, Mitchell B, Brillant M, Dienaar R, Hughes J, Lau P, Peterson G, Stewart K, Taylor S, et al. The pharmacy diabetes care program: assessment of a community pharmacy diabetes service model in Australia. Diabet Med. 2007;24(6):677-83.

55. García-Cárdenas V, Sabater-Hernández D, Kenny P, Martínez-Martínez F, Faus $\mathrm{MJ}$, Benrimoj SI. Effect of a pharmacist intervention on asthma control. A cluster randomised trial. Respir Med. 2013;107(9):1346-55.
56. Hawksworth C, Wright C. Clinical pharmacy interventions by community pharmacists during the dispensing process. Br J Clin Pharmacol. 1999;47(6): 695-700.

57. Stewart DW, Brown SD, Clavier CW, Wyatt J. Active-learning processes used in US pharmacy education. Am J Pharm Educ. 2011;75(4):68.

58. Kaboli PJ, Hoth AB, McClimon BJ, Schnipper JL. Clinical pharmacists and inpatient medical care: a systematic review. Arch Intern Med. 2006; 166(9):955-64.

59. Cabello-Muriel A, Gascon-Canovas JJ, Urbieta-Sanz E, Iniesta-Navalon C. Effectiveness of pharmacist intervention in patients with chronic kidney disease. Int J Clin Pharm. 2014;36(5):896-903.

60. Tilly-Gratton A, Lamontagne A, Blais L, Bacon SL, Ernst P, Grad R, Lavoie KL, McKinney ML, Desplats E, Ducharme FM. Physician agreement regarding the expansion of pharmacist professional activities in the management of patients with asthma. Int J Pharm Pract. 2017;25(5):335-42.

61. Hall JJ, Katz SJ, Cor MK. Patient satisfaction with pharmacist-led collaborative follow-up Care in an Ambulatory Rheumatology Clinic. Musculoskeletal Care. 2017;15(3):186-95.

62. Proper JS, Wong A, Plath AE, Grant KA, Just DW, Dulhunty JM. Impact of clinical pharmacists in the emergency department of an Australian public hospital: a before and after study. Emerg Med Australas. 2015;27(3):232-8.

63. Buurma H, De Smet PAGM, Leufkens HGM, Egberts ACG. Evaluation of the clinical value of pharmacists' modifications of prescription errors. $\mathrm{Br} J \mathrm{Clin}$ Pharmacol. 2004;58(5):503-11.

64. van Grootheest AC, de Jong-van den Berg LT. The role of hospital and community pharmacists in pharmacovigilance. Res Social Adm Pharm. 2005; 1(1):126-33.

65. Woolf R, Locke A, Potts C. Pharmacist prescribing within an integrated health system in Washington. Am J Health Syst Pharm. 2016;73(18): 1416-624.

66. Emmerton LM, Smith L, LeMay KS, Krass I, Saini B, Bosnic-Anticevich SZ, Reddel HK, Burton DL, Stewart K, Armour CL. Experiences of community pharmacists involved in the delivery of a specialist asthma service in Australia. BMC Health Serv Res. 2012;12:164.

67. Keeys C, Kalejaiye B, Skinner M, Eimen M, Neufer J, Sidbury G, Buster N, Vincent J. Pharmacist-managed inpatient discharge medication reconciliation: a combined onsite and telepharmacy model. Am J Health Syst Pharm. 2014;71(24):2159-66.

68. Milone AS, Philbrick AM, Harris IM, Fallert CJ. Medication reconciliation by clinical pharmacists in an outpatient family medicine clinic. J Am Pharm Assoc (2003). 2014;54(2):181-7.

69. Eisenhower C. Impact of pharmacist-conducted medication reconciliation at discharge on readmissions of elderly patients with COPD. Ann Pharmacother. 2014;48(2):203-8.

70. Castelino RL, Bajorek BV, Chen TF. Retrospective evaluation of home medicines review by pharmacists in older Australian patients using the medication appropriateness index. Ann Pharmacother. 2010;44(12):1922-9.

71. Zermansky AG, Petty DR, Raynor DK, Freemantle N, Vail A, Lowe CJ. Randomised controlled trial of clinical medication review by a pharmacist of elderly patients receiving repeat prescriptions in general practice. Br Med J. 2001;323(7325):1340

72. Schuessler TJ, Ruisinger JF, Hare SE, Prohaska ES, Melton BL. Patient satisfaction with pharmacist-led chronic disease state management programs. J Pharm Pract. 2016;29(5):484-9.

73. Awalom MT, Kidane ME, Abraha BW. Physicians' views on the professional roles of pharmacists in patient care in Eritrea. Int J Clin Pharm. 2013;35(5):841-6.

74. Laubscher T, Evans C, Blackburn D, Taylor J, McKay S. Collaboration between family physicians and community pharmacists to enhance adherence to chronic medications: opinions of Saskatchewan family physicians. Can Fam Physician. 2009;55(12):e69-75.

75. Khan MU, Arief M, Ahmad A, Malik S, Gogoi L, Kalita M, Saleem F, Hassali MAA. A cross-sectional survey on the attitudes and interests of rural population towards expanded pharmacist prescribing in India. Int J Clin Pharm. 2017;39(2):473-7.

76. Sansgiry SS, Bhansali AH, Mhatre SK, Sawant RV. Influence of patient perceived relationship with pharmacist and physician and its association with beliefs in medicine. J Pharm Health Serv Res. 2017;8(2):123-30.

77. Altowaijri A, Phillips CJ, Fitzsimmons D. A systematic review of the clinical and economic effectiveness of clinical pharmacist intervention in secondary prevention of cardiovascular disease. J Manag Care Pharm. 2013;19(5):408-16. 
78. Huttner B, Harbarth S, Nathwani D. Success stories of implementation of antimicrobial stewardship: a narrative review. Clin Microbiol Infect. 2014; 20(10):954-62.

79. Goff DA, Kullar R, Goldstein EJC, Gilchrist M, Nathwani D, Cheng AC, Cairns KA, Escandón-Vargas K, Villegas MV, Brink A, et al. A global call from five countries to collaborate in antibiotic stewardship: united we succeed, divided we might fail. Lancet Infect Dis. 2017;17(2):56-63.

80. von Gunten V, Reymond JP, Beney J. Clinical and economic outcomes of pharmaceutical services related to antibiotic use: a literature review. Pharm World Sci. 2007;29(3):146-63.

81. MacLaren R, Bond CA, Martin SJ, Fike D. Clinical and economic outcomes of involving pharmacists in the direct care of critically ill patients with infections. Crit Care Med. 2008;36(12):3184-9.

82. Holmes AH, Sharland M. The Chennai declaration: India's landmark national commitment to antibiotic stewardship demonstrates that 'truth alone triumphs. J Antimicrob Chemother. 2013;68(7):1453-4.

83. Sharma M, Damlin AL, Sharma A, Lundborg CS. Antibiotic prescribing in medical intensive care units - a comparison between two private sector hospitals in Central India. Infect Dis. 2015;47(5):302-9.

84. Islam MS, Farah SS. Misleading promotion of drugs in Bangladesh: evidence from drug promotional brochures distributed to general practioners by the pharmaceutical companies. J Public Health. 2007:29(2):212-3.

85. Parthasarathi G, Ramesh M, Kumar JK, Madaki S. Assessment of drug-related problems and clinical Pharmacists' interventions in an Indian teaching hospital. J Pharm Pract Res. 2003;33(4):272-4.

86. Dyar OJ, Beovic B, Vlahovic-Palcevski V, Verheij T, Pulcini C. How can we improve antibiotic prescribing in primary care? Expert Rev Anti Infect Ther. 2016;14(4):403-13.

87. Azhar S, Hassali M, Ibrahim M. Doctors' perception and expectations of the role of the pharmacist in Punjab, Pakistan. Trop J Pharm Res. 2010; 9(3):205-22.

88. Coombes I, Coombes J, Dawson A. Clinical pharmacy in Sri Lanka: translating training into practice. J Pharm Pract Res. 2015;45(4):392-3.

89. Coombes ID, Fernando G, Wickramaratne DBM, Peters NB, Lynch C, Lum E, Coombes JA. Collaborating to develop clinical pharmacy teaching in Sri Lanka. Pharm Education. 2013;13:2013.

90. Khan HMS, Butt H, Shah NH. PHP124 - exposure to potential drug-drug interactions in teaching hospital of South Punjab, Pakistan. Value Health. 2014;17(7):A425.

91. Lingenfelter E, Drapkin Z, Fritz K, Youngquist S, Madsen T, Fix M. ED pharmacist monitoring of provider antibiotic selection aids appropriate treatment for outpatient UTI. Am J Emerg Med. 2016;34(8):1600-1603.

92. LaRochelle JM, Ghaly M, Creel AM. Clinical pharmacy faculty interventions in a pediatric intensive care unit. J Investig Med. 2011;59(2):422-3.

93. Roque F, Teixeira-Rodrigues A, Breitenfeld L, Pineiro-Lamas M, Figueiras A, Herdeiro MT. Decreasing antibiotic use through a joint intervention targeting physicians and pharmacists. Future Microbiol. 2016;11:877-86.

94. Arya V, Pinto S, Singer J. Understanding awareness of pharmacist-led medication therapy management among primary care physicians in new York City, part II: findings and implications. J Med Pract Manage. 2013;29(3):187-94

95. Gupta A. Antimicrobial stewardship: think global, act local. Int J Infect Dis. 2014;21:74-5.

96. Leguelinel-Blache G, Dubois F, Bouvet S, Roux-Marson C, Arnaud F, Castelli C, Ray V, Kinowski JM, Sotto A. Improving Patient's primary medication adherence: the value of pharmaceutical counseling. Medicine. 2015;94(41):e1805.

97. Brink AJ, Messina AP, Feldman C, Richards GA, van den Bergh D. From guidelines to practice: A pharmacist-driven prospective audit and feedback improvement model for peri-operative antibiotic prophylaxis in 34 South African hospitals. J Antimicrob Chemother. 2017:72(4):1227-234.

Ready to submit your research? Choose BMC and benefit from:

- fast, convenient online submission

- thorough peer review by experienced researchers in your field

- rapid publication on acceptance

- support for research data, including large and complex data types

- gold Open Access which fosters wider collaboration and increased citations

- maximum visibility for your research: over $100 \mathrm{M}$ website views per year

At BMC, research is always in progress.

Learn more biomedcentral.com/submissions 